\title{
Pênfigo Foliáceo Endêmico (Fogo-Selvagem) no Grupo Indígena Xavánte, Mato Grosso, Brasil ${ }^{1}$
}

\section{Endemic Pemphigus Foliaceus Among The Xavánte Indians, State of Mato Grosso, Brazil}

Horácio Friedman ${ }^{2}$; Carlos E. A. Coimbra Jr. ${ }^{3}$; Rosicler R. Alvarez ${ }^{2}$; Iphis Campbell ${ }^{2}$; Luiz A. Diaz ; Nancy M. Flowers ${ }^{5}$; Ricardo V. Santos ${ }^{3}$; Maria L. Bertoli ; Glória B. M. N. Gama ${ }^{2}$; Monica C. O. Alcalá ${ }^{4}$

FRIEDMAN, H.; COIMBRA Jr., C. E. A.; ALVAREZ, R R; CAMPBELL, I; DIAZ, L. A.; FLOWERS, N. M.; SANTOS, R. V.; BERTOLI, M. L; GAMA. G. B. M. N. \& ALCALA, M. C. O. Endemic Pemphigus Foliaceus Among The Xavánte Indians, State of Mato Grosso, Brazil. Cad. Saude Públ., Rio de Janeiro, 8 (3): 331-334, jul/set, 1992.

A sero-epidemiological survey was carried out by means of indirect immunofluorescence and immunoprecipitation tests in order to determine the prevalence of endemic pemphigus foliaceus $(E P F)$ among the Xavánte Indians from Central Brazil. Out of 163 serum samples, 5 (3.1\%) tested positive for immunofluorescence. All positive sera were from patients showing clinical signs of the disease. The immunological features of EPF among the Xavante do not differ from those of non-Indian populations, as was observed a predominance of IgG4 among the antibodies of the Indian subjects.

Keywords: Pemphigus Foliaceus; Sero-Epidemiology; Immunology; Indians; Central Brazil

\section{INTRODUÇÃO}

O pênfigo foliáceo endêmico (PFE), ou fogo selvagem, ocorre com elevada prevalência e freqüente distribuição familiar na América Latina. No Brasil, estima-se que há atualmente mais de 15.000 casos, acometendo predominantemente adultos jovens (Diaz et al., 1989). O número de casos de PFE é tão elevado em algumas regiões do Brasil e principalmente no

\footnotetext{
'Trabalho realizado com auxilio da Wenner-Gren Foundation for Anthropological Research (\# 95230), da Fundação Mata Virgem e da Fundação Nacional do Indio.

${ }^{2}$ Laboratório de Patologia e Unidade de Dermatologia da Faculdade de Ciencias da Saúde da Universidade de Brasilia, Brasília, DF, 70910-900, Brasil.

${ }^{3}$ Núcleo de Doenças Endèmicas Samuel Pessoa da Escola Nacional de Saúde Pública. Rua Leopoldo Bulhões, 1480, Rio de Janeiro, RJ, 21041 -210, Brasil.

- Department of Dermatology. Medical College of Winsconsin, Milwaukee, WI 53226, U.S.A.

'Department of Anthropology, City University of New York, 695. Park Avenue, New York, NY 10021, U.S.A.
}

Centro-Oeste, que existem hospitais especializados em seu tratamento (Diaz et al., 1989).

No Estado de Mato Grosso, as áreas indígenas Xavánte são reconhecidas no meio indigenista como de alta endemicidade para o PFE. Infelizmente, são escassos os dados de morbidade para as diversas aldeias Xavánte, dificultando não apenas o cômputo de casos, como também a obtenção de informações sobre sexo, idad :, relações de parentesco e aspectos clínicos dos pacientes.

Como parte de pesquisa pioneira sobre as condiçōes de saúde e biologia dos Xavánte, Weinstein et al. (1967) identificaram pela primeira vez o PFE na população. Os autores descreveram o caso de um paciente jovem, do sexo masculino, com o que hoje denominariamos forma generalizada da doença. Auad (1972) refere a existência de casos de pènfigo entre indigenas do Brasil Central, particularmente os Xerénte e os Karajá. Afora estes trabalhos, inexistem outros que lidem, detalhadamente, com aspectos epidemiológicos e/ou 
clínicos do pênfigo entre populaçōes indígenas brasileiras.

Este trabalho apresenta os resultados preliminares de um inquérito soro-epidemiológico sobre o pênfigo entre os Xavánte visando determinar sua prevalència na população. As investigações laboratoriais também tiveram por objetivo caracterizar as classes e subclasses de imunoglobulinas, bem como a reatividade contra antígenos já reconhecidos do PFE nos soros positivos.

\section{MATERIAL E MÉTODOS}

Foi estudada a população Xavánte da aldeia Rio das Mortes, Área Indígena Pimentel Barbosa, Estado de Mato Grosso $\left(52^{\circ} \mathrm{W} 13^{\circ} \mathrm{S}\right)$. A população total da aldeia em junho de 1990 era de 461 indivíduos, quando as amostras de soro foram coletadas. Foram testadas sorologicamente 158 amostras de pacientes assintomáticos ao exame dermatológico e 5 oriundas de pacientes com sintomatologia clínica de pênfigo, totalizando 163 amostras. Indivíduos de ambos os sexos e diversas faixas etárias foram incluídos no estudo. Os soros foram testados por imunofluorescência indireta, conforme método previamente padronizado para identificação das classes e subclasses de imunoglobulina (Friedman et al., 1989). Os soros positivos foram posteriormente submetidos a teste de reatividade por imunoprecipitação contra antígenos de PFE marcados radioativamente com ${ }^{125}$ I (Calvanico et al., 1991).

\section{RESULTADOS}

Dentre as 163 amostras testadas, $5(3,1 \%)$ apresentaram reação positiva ao exame de imunofluorescência, sendo todas provenientes de pacientes do sexo feminino. Os soros positivos provieram, em sua totalidade, daqueles pacientes com sintomas clínicos da doença. A subclasse dominante foi a IgG4 (Tabela 1).

Os testes de imunoprecipitação com os antígenos de PFE foram positivos nas 5 amostras, com reações nas mesmas bandas observáveis em pacientes não-Xavánte com PFE (Figura 1). Os testes foram negativos para controles normais (Xavánte e não-Xavánte sem PFE).

\section{DISCUSSÃO}

Os resultados deste estudo permitem que, pela primeira vez, obtenha-se uma estimativa da prevalência da doença (i.e., 3,1\%) para uma população brasileira. Por não terem sido realizados inquéritos sorológicos semelhantes a nivel local ou nacional, torna-se difícil comparar os resultados Xavánte com os de outras populaçōes.

Clinicamente, o PFE observado entre os Xavánte não difere das formas conhecidas para a população em geral (cf. Friedman, 1992, para maior detalhamento sobre a clínica e imunogenética do PFE entre os Xavánte). Sorologicamente, a predominância da IgG4 entre os auto-anticorpos, tanto nos pacientes Xavánte como nos não-Xavánte, demonstra semelhança

TABELA 1. Títulos de Anticorpos e Reações de Imunoprecipitação em Pacientes Xavánte com Pênfigo Foliáceo Endêmico (PFE)

\begin{tabular}{lcccccccc}
\hline \hline Paciente & Sexo & Idade & IgGt & IgG1 & IgG2 & IgG3 & IgG4 & IP $^{*}$ \\
\hline 0305 & F & 51 & 80 & 0 & 0 & 0 & 320 & + \\
0802 & F & 38 & 160 & 20 & 0 & 0 & 320 & + \\
1306 & F & 12 & 320 & 20 & 0 & 0 & 320 & + \\
0609 & F & 26 & 320 & 0 & 0 & 0 & 320 & + \\
2202 & F & 28 & 320 & 0 & 0 & 0 & 1280 & + \\
\hline \hline
\end{tabular}

* IP: Teste de Imunoprecipitação com Antigenos de PFE. 
FIGURA 1. Auto-radiografia de imunoprecipitados contendo antígenos de PFE marcados com ${ }^{125}$ I. Os círculos negros indicam marcadores de peso molecular. Os asteriscos indicam as faixas antigênicas precipitadas pelos anticorpos séricos. A coluna 1 corresponde a soro de paciente não-Xavánte com PFE, no qual demonstraram-se previamente as frações antigênicas de $45 \mathrm{kD}, 62 \mathrm{kD}$ e $80 \mathrm{kD}$. As colunas 2 a 6 correspondem aos cinco soros de pacientes Xavánte com PFE, reagentes contra os antígenos. As colunas 7 e 8 correspondem a soros Xávante sem PFE. A coluna 9 corresponde a soro normal de individuo não-Xavánte

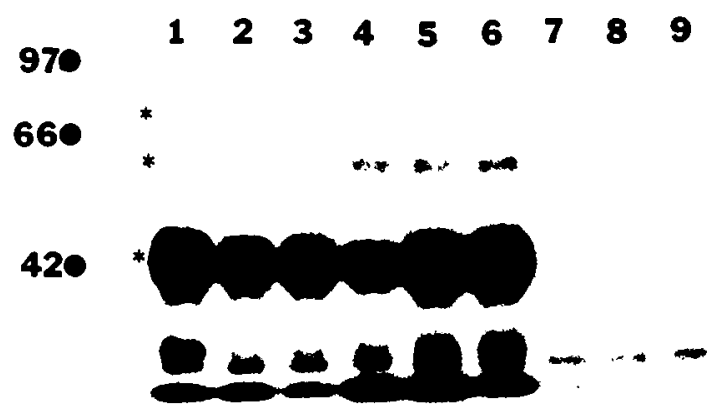

de comportamento da resposta imunológica. Também houve similaridade quanto à reatividade dos auto-anticorpos, o que sugere que o mesmo sistema antígeno-anticorpo esteja envolvido na resposta imunológica dos Xavánte e da população em geral. Em suma, os resultados apontam para a similaridade do PFE entre os Xavánte quando comparado com a doença entre indivíduos não-Xavánte, possivelmente envolvendo os mesmos fatores ambientais desencadeadores.

Os fatores ambientais que desencadeiam a doença permanecem desconhecidos. Dentre as várias hipóteses, destaca-se aquela que relaciona o surgimento da doença à exposição a picadas de insetos hematófagos e, particularmente, aos dípteros simulídeos (Auad, 1972). Os simulideos são comuns nas regiões ribeirinhas onde o pênfigo é endêmico, incluindo-se aí a área Xavánte, onde os mesmos abundam, principalmente nos meses de chuva.

Os achados deste trabalho apontam para a necessidade de prosseguir-se com as investigações sobre a epidemiologia e imunopatologia do pênfigo entre os Xavánte. Chama-se também atenção para a importância de acompanhamento dos casos de PFE detectados, o que tem sido feito por nosso grupo de pesquisa.

\section{RESUMO}

FRIEDMAN, H.; COIMBRA Jr., C. E. A.; ALVAREZ, R. R.; CAMPBELL, I.; DIAZ, L. A.; FLOWERS, N. M.; SANTOS, R. V.; BERTOLI, M. L.; GAMA. G. B. M. N. \& ALCALA, M. C. O. Pênfigo Foliáceo Endêmico (Fogo-Selvagem) no Grupo Indígena Xavánte, Mato Grosso, Brasil. Cad. Saúde Públ., Rio de Janeiro, 8 (3): 331334, jul/set, 1992.

Foi realizado inquérito soro-epidemiológico através de testes de imunofluorescência indireta e imunoprecipitação visando determinar a prevalência do pênfigo foliáceo endêmico (PFE) na população indígena Xavánte do Brasil Central. Do total de 163 amostras de soro testadas, $5(3,1 \%)$ foram positivas à imunofluorescência. Todos os soros positivos procediam de indivíduos com sintomas clínicos da doença. Não foram observadas diferenças do PFE entre os Xavánte e a população em geral sob o ponto de vista imunológico, já que se verificou uma predominância da IgG4 entre os anticorpos nos pacientes indígenas.

Palavras-Chave: Pênfigo Foliáceo; Soro-Epidemiologia; Imunologia; Indios; Brasil Central 


\section{REFERÊNCIAS BIBLIOGRÁFICAS}

AHMED, A. R., 1983. Clinical features of pemphigus. Clinical Dermatology, 1: 13-21.

AUAD, A., 1972. Pênfigo foliáceo sul-americano no Estado de Goiás. Revista de Patologia Tropical, 1: 293-346.

CALVANICO, N. J.; MARTINS, C. Z. \& DIAZ, L. A., 1991. Characterization of pemphigus foliaceus antigen from human epidermis. Journal of Investigative Dermatology, 96: 815-821.

FRIEDMAN, H., 1992. Pênfigo Foliáceo Entre os Xavánte: Estudos Imunológicos e Imunogenéticos da Reação Auto-Imune. Tese de Doutorado, Brasilia: Faculdade de Ciências da Saúde, Universidade de Brasilia.
FRIEDMAN, H.; CAMPBELL, I. T.; ALVAREZ, R. R.; DIAZ, L. A.; CASTRO, R. M.; ROITMAN, I.; PARREIRAS, R. M. \& RAICK, A. N., 1989. Imunofluorescência indireta no pênfigo foliáceo endêmico. Contribuição para a sua padronização. Revista do Instituto de Medicina Tropical de São Paulo, 31: 158-168.

WEINSTEIN, E. D.; NEEL, J. V. \& SALZANO, F. M., 1967. Further studies on the Xavante Indians. VI. The physical status of the Xavantes of Simões Lopes. American Journal of Human Genetics, 19: 532-542. 